\title{
FORENSIC ENGINEERING ANALYSIS OF BUILDING STRUCTURES IN INDONESIA: A CASE STUDY OF THE COLLAPSE OF THE MAHAKAM II KUTAI KARTANEGARA BRIDGE IN EAST BORNEO
}

\author{
Kamaluddin*, Researcher \\ Wahyono Agus Hari, Iskandar Tiong, Lecturers \\ National Institute of Technology, Malang, East Java, Indonesia \\ *E-mail: kamalludin.kl@gmail.com \\ ORCID: 0000-0002-8383-7062
}

\begin{abstract}
The objectives of this research are: 1) to provide an overview of the analysis of forensic engineering in bridge structures, 2) to obtain an overview of the application of forensic engineering in Indonesia. Analysis of forensic engineering in building structures in Indonesia goes through se veral stages. It starts from the preparatory work, then continues with the process of identifying data needs, identifying problems, and preparing literature studies. If the data is sufficient, then it will be proceeded to the data analysis and discussion process. Based on the research findings, the main cause of the collapse of the Mahakam II Bridge in Tenggarong was the construction failure of the vertical hanging cable (clamp and saddle) connecting the main cable. However, there are a number of other possibilities that cause damage to the connecting device which includes: 1) poor maintenance, 2) fatigue in the construction material of cable hangers, 3 ) the quality of construction materials for the cable of connecting device, 4) procedural errors in maintenance, 5 ) the possibility of civil engineering rules deviations in planning, and 6) design errors in determining the type of material/ material of connecting device. Commonly, building damage is caused by several factors including: 1) low quality of materials, 2) planning errors, 3) implementation process errors, and 4) poor supervision.
\end{abstract}

\section{KEY WORDS}

Analysis, forensic engineering, building structure, bridge.

In building the infrastructure, the government aims to improve the economy of regions throughout the archipelago. The infrastructure is in the form of roads, bridges, and other supporting facilities. In supporting the central government's program, the Government of Kutai Kartanegara Regency also has an important role. That was proven by the construction of the Mahakam II Kutai Kartanegara Bridge that connects Samarinda City with Kutai Kartanegara Regency. However, after standing firmly for 10 years, the public was shocked by the collapse of the Mahakam II Kutai Kartanegara Bridge that connected Samarinda and Tenggarong in East Borneo. The bridge, which was built in 1995 and started operating in 2001, collapsed causing casualties, injuries, and not a few material losses. The collapse occurred on November 26, 2011, around 3:00 p.m. In this case, the cause of the collapse cannot be revealed in an instant, because it requires further research and examination. However, the forensic investigation team has been working to find the cause of the collapse. The cause is still being investigated by competent experts. It is not easy to find the cause of the collapse of the bridge structure.

However, not all causes of damage to buildings and infrastructure are due to nature. There are also causes resulted by construction and technical failures during project implementation. Construction failure is a technical and non-technical failure. This failure can be caused by failure in the process of procurement of goods or services and also failure during the construction process. Failure of construction work is the condition when the results of construction work is not in accordance with the specifications of the work as agreed in the construction work contract either partially or wholly as a result of errors in service users or 
providers. (Government Regulation 29/2000 article 31 concerning Organizing Construction Services).

Obtaining the causes of construction failure is not easy. The source of failure itself is often an accumulation of various factors. Wiyana (2016) stated that "construction defects" in America were caused by human factors $(54 \%)$, design $(17 \%)$, maintenance $(15 \%)$, material $(12 \%)$, and unexpected things (2\%). Vickynason (2003) stated that $80 \%$ of total projects risk in construction is caused by human factors. Meanwhile, Carper (1989) stated that the potential causes of construction failure in general are site selection and site development errors, programing deficiencies, construction errors, material deficiencies and operational errors.

Factors that affect project failure are the allocated construction costs, quality of work implementation, and implementation time. Construction failures in buildings occur in the failure of structural elements with an average deviation of $4.36 \%$ from the contract value, roof elements $2.53 \%$, foundation $0.15 \%$, utilities $0.12 \%$ and finishing $0.07 \%$ (Wahyono et. al., 2011). The success of the construction project depends on the role of the supervisor. The model of the internal supervisor (contractor) and external supervisor (supervisor consultant) have a significant effect on the quality of the project. Thus, compliance with the supervisory professional code of ethics is required to strengthen the supervisory function, which is contained in the Certificate of Expertise Decree. Internal factors of supervision (contractors) affect the quality and external supervision (supervisory consultant). Meanwhile, the quality factor is very dependent on external supervision.

Particularly, when a professional engineer testifies as an expert witness before the court for an engineering problem that is closely related to his expertise concerning the interests of the public, the engineer is currently serving as a forensic engineer (Mitchell, 2004). On that occasion, a forensic engineer must be able to explain the problem objectively, logically, factually, neutrally, unbiasedly and use language that is easily understood by laymen on how to conduct investigations to obtain findings of evaluation and analysis techniques, evaluation/ analysis results, conclusions, opinions and recommendations. In this condition, those various parties include court institutions, police, local government authorities related to building permits, insurance, building owners, planner/ supervisor consultants, and contractors that involved in the construction implementation (Hobbs \& Kebir, 2007).

Research Problems:

- How is the analysis of forensic engineering in the structure of the Mahakam II Kutai Kartanegara Bridge?

- How is the application of the analysis of forensic engineering to building structures in Indonesia?

Research Objectives:

- Provide an overview of the analysis of forensic engineering on the structure of the Mahakam II Kutai Kartanegara Bridge;

- Obtain an overview of the application of forensic engineering in Indonesia.

\section{METHODS OF RESEARCH}

This research was carried out at the Public Works Agency, Kutai Kartanegara Regency, East Borneo Province because the supporting data of the research were closely related to this agency. In addition, the results of the investigation into the collapse of the Mahakam II Kutai Kartanegara Bridge were recorded in this agency.

The supporting data for this case study is broadly taken from secondary data. The data were obtained from other parties or related agencies. In other words, this research uses the existing data, i.e. the results of forensic engineering from the Government of Kutai Kartanegara Regency; in this case the Public Works Agency.

Analysis of forensic engineering in building structures in Indonesia goes through several stages. It starts from the preparatory work, and then continues with the process of identifying data needs, identifying problems, and preparing literature studies. If the data is sufficient, then it will be proceeded to the data analysis and discussion process. Analysis and 
discussion of the data go through manual processing methods. The results of the above analysis produce several settlements/ solutions that can be used to overcome the problems. Then, then conclusions can be taken and the best method for resolution can be chosen.

Basically, the process of building a skyscraper, starting from the design stage to the implementation stage, requires careful planning and time. That includes very complex structural calculations, the number of strict rules starting from calculating the strength of foundation support, calculating the size and composition of column beam structures, building resilience to static loads, dynamic loads and estimated earthquake loads that might be faced by these buildings.

In the past, building experts designed earthquake-resistant buildings by planning the main structure (beam-column) that is so rigid and strong, in order not to crack during an earthquake. This is implemented by designing column structures and beams with large dimensions and with tight steel reinforcement. That of course will require a much greater and expensive cost. Related to the possibility of the magnitude of the earthquake inertia forces acting at the center of the building mass, construction experts argue that it is not economical to plan general structures that are too strong and rigid. So, elasticity is also needed when a strong earthquake is struck.

The Indonesian Government, in "Guidelines for Planning Earthquake Resilience for Houses and Buildings. SKBI 1.3.53. Department of Public Works 1987", establishes a plan for seismic load levels that ensures a structure is not damaged due to small or medium earthquakes. However, when it is hit by a strong earthquake, which is rare, the structure can behave ductile by distributing earthquake energy and simultaneously limiting the earthquake load that enters the structure.

When a strong earthquake hits, structures that are planned to behave in an elastic manner must be able to carry the earthquake load. This is obtained by planning the formation of plastic joints at beam and column meetings (Johnson, 2011). In planning earthquake resistant buildings, the formation of joints, that are capable of dispersing earthquake energy and limiting the magnitude of the earthquake load that enters the structure, must be controlled in such a way that the structure behaves satisfactorily and does not collapse during a strong earthquake (Ghobarah \& Said, 2002).

Control of the formation of plastic joints, at predetermined locations, can be carried out with certainty; regardless of the strength and characteristics of the earthquake. This planning philosophy is known as the design capacity concept. One example of the application of the design capacity concept lies in the industrial world which aims to ensure human security and other infrastructure around it. In car design, for example, there is a "steel safety cage" system. It is a steel frame system around the "body" that is specifically designed to protect passengers and drivers from front and rear collisions. In this case, the variety of damage has been determined in advance by making the "body" or the center of the car stronger than the front and rear (Bernquist, 2004). With the same concept, to deal with strong earthquakes that may occur in a certain period of time (for example 200 years), the collapse mechanism of a portal for reinforced concrete frames is chosen in such a way so that the distribution of earthquake energy is satisfactory.

Principally, by using the capacity design concept, the main elements of earthquake resistance can be chosen so that the columns are stronger than the portal beams (strong column-weak beam). Thus, the building is able to distribute earthquake energy with considerable inelastic deformation without collapsing. In addition, the mechanism of the building that has been selected can be maintained during a strong earthquake. Earthquakeresistant building design is a building plan that adds an earthquake load plan to the calculation of the load to be received by the structure in addition to normal, vertical and wind loads.

Earthquake load, basically, is dynamic with uneven amplitude. The simplification of the dynamic earthquake load is carried out by recording the history of earthquakes that have occurred in an area where the location of the building will be built and simplifying it into a static equivalent load that will be received at each joint meeting of columns and beams which 
cause deviation $(\mathrm{y})$ and moment. Then, the planned structure must be able to withstand the working loads as modeling earthquake loads (Sezen et al., 2003).

Structural errors caused by human error or natural factors. The damage has varying degrees including minor damage to severe damage that has the potential to cause collapse. Actually, these structural errors can be prevented or minimized so that the impact is not too large. Even so, basically, there are several types of structural errors that cannot be handled by contractors. Several causes of structural errors can be detected after a thorough investigation of the entire building. Factors causing structural damage to buildings include the following description, (Ellingwood \& Dusenberry, 2005).

One of the most frequent causes of structural failure in buildings is poor building design. For instance, technicians or designers make computational errors or calculations during the building design process. In addition, that may occur due to the inaccurate data, poor material selection, or neglection of the factors that can affect the pressure on the building. Errors involving this calculation are the responsibility of the technician, especially the civil technician because they are the ones responsible for making the blueprint and design plan for a building.

A building is designed to withstand certain conditions; depending on the function and environment around it. When these conditions exceed the limit, it can cause structural errors. For example, a roof of a building has been designed to hold moderate intensity rainwater. When heavy rains occur, the roof will automatically be quite difficult to hold the load. Moreover, if the roof is not equipped with an appropriate drainage system, a lot of water will pile up on the roof which gives an additional load on the roof. It will get worse if ash falls occur. Ash heaps, sand and rock materials have the potential to cause the roof to be unable to withstand the load and eventually collapse.

Buildings located in disaster-prone areas, such as landslides, tornado or volcanic ash, should have a more solid building structure and roof structure. A solid building structure will be able to prevent or at least reduce the impact of building damage when these disasters suddenly occur.

Commonly, construction defects occur when the contractor uses wrong or incorrect material in the construction of a house or building. Usually, the foreman or building inspector will immediately know this error so that it can be repaired immediately before the construction process is completely finished. However, if the building inspector is negligent in monitoring this matter, new construction defects will be found out after the construction is almost complete. The impact of this construction defect is bad welds, sand that still contains too much salt to be made into concrete, bad riveting and inferior steel.

A well-designed building structure in an unstable foundation condition can cause construction errors. One example of a building with a bad foundation and causing a fatal error is the Pisa Tower in Italy. A bad foundation causes the building to lean a few degrees because the ground below it moves. Displacement changes the pressure distribution in a building, so the construction and design of a building changes from the original plan, and is no longer feasible to function because it can collapse at any time.

The condition of Indonesia, as an archipelago country, certainly has a lot of building structures and bridges located in coastal areas that are in a fairly aggressive environment. Aggressive in this case refers to the coastal environment has a high chloride content in air and water that can corrode. Although most of these coastal structures, especially bridges, are made of reinforced concrete, they can be affected by corrosion. Moreover, if the manufacturing process has a low-quality work, the concrete will not be solid or porous and have thick blankets that are less than the requirements.

Corrosion in ordinary reinforced concrete or passive reinforced concrete has more impact on the decline in service structure (serviceability) in the form of cracks, spalling, loss of attachment, or staining. If no repairs are made, the reduced dimensions of reinforcing steel will cause reduced structural strength. That can lead to overall structural failure. Meanwhile, in the full prestressed concrete structure, which is a concrete structure with active reinforcement, the corrosion effect on prestressed steel is more risky than ordinary reinforced concrete. Corrosion in prestressed concrete can cause direct structural failure if the stress on 
prestressed steel exceeds the reduced capacity due to corrosion. In addition, the diameter of prestressed steel (active) which is relatively smaller than reinforced steel (passive) can receive a faster corrosion effect in the same time period and with the same corrosion rate.

To make it easier to carry out the analysis, the author only reviews in depth one case example of forensic engineering analysis of the collapse of the Mahakam II Bridge located in Kutai Kartanegara Regency, East Borneo. The Kutai Kartanegara Mahakam II Bridge is one of the longest suspension bridges in Indonesia, where the bridge has the following specifics: a total length of 710 meters with a main span of 270 meters and free space of 15 meters with vertical clearance of 5 meters. It began construction since August 17, 1995 and was completed in 2001. The location of the Mahakam II Kutai Kartanegara Bridge can be clearly seen in the following picture:

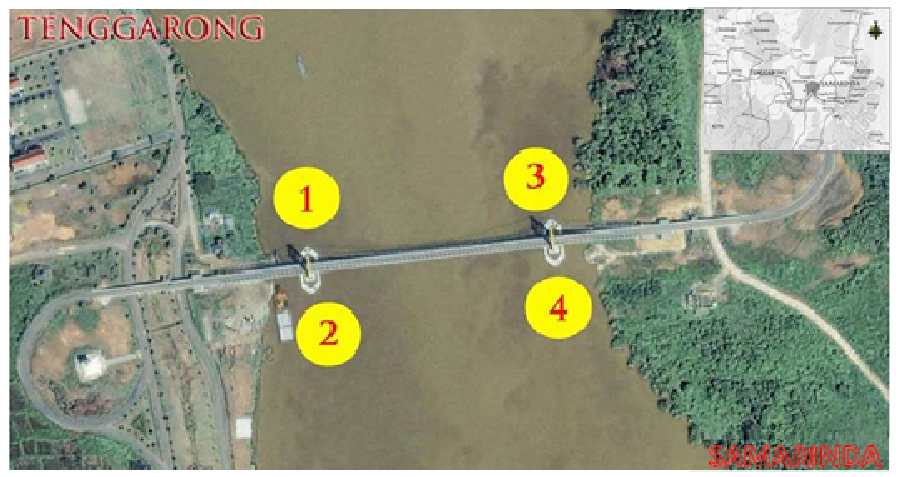

Figure 1 - Location of Mahakam II Bridge, Tenggarong (Google Earth, 2016)

In addition, a brief overview of the main components of Mahakam II Kutai Kartanegara Bridge in Tenggarong can be seen in the following picture:

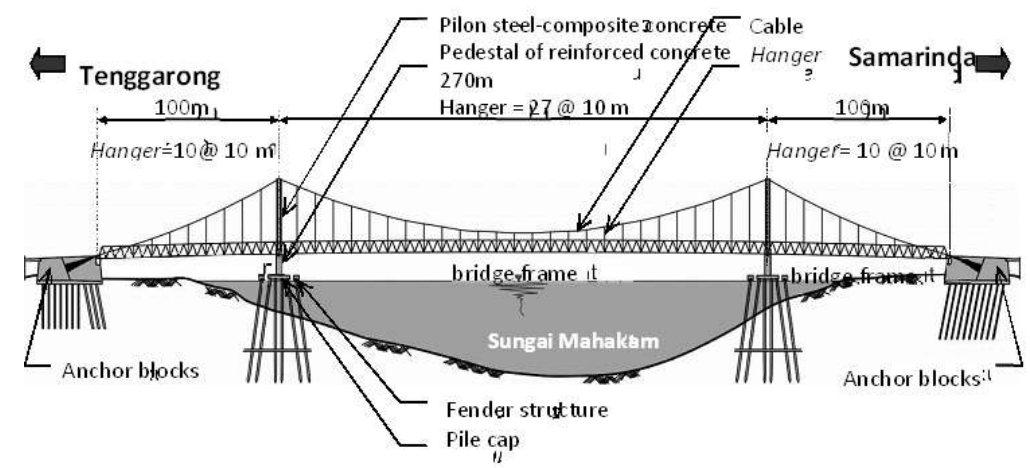

Figure 2 - The Main Components of Mahakam II Kutai Kartanegara Bridge in Tenggarong

The bridge frame is used as a stiffening girder which also carries directly the floor of the vehicle. The bridge is generally in the form of a steel space truss which consists of plane trusses which are stretched with a girder that crosses a 5-meter sphere at the bottom, and wind bonds at the top. The bridge frame is given a camber which changes slowly from zero at both ends to approximately 3.8 meters in the middle of the span.

The reconnaissance survey found a type of structural component in the form of a pull rod that was used as a hanging bridge frame directly to pilons (not through suspension cables, see Figure 11). This structural component is called a tower strap (TS). The dimensions of the tower strap are large enough so that the stiffness is also greater than a standard hanger. The pedestal nature of the tower strap is a roller in a small deviation; however, it can turn into a joint at a larger junction. In the vertical direction the movement of the bridge frame is locked due to the tower strap, while the lateral direction is restrained by the stopper. 
It is not experienced by all remaining points that are attached to the hanger. Cable band is commonly used on suspension bridges as a connecting component between hanger and suspension cable. At the Kutai Kartanegara Bridge, the components are not cable bands as they are commonly used. However, to facilitate the discussion in this paper, these components are still referred to as cable bands. The cable bands component is shown in Figure 4.

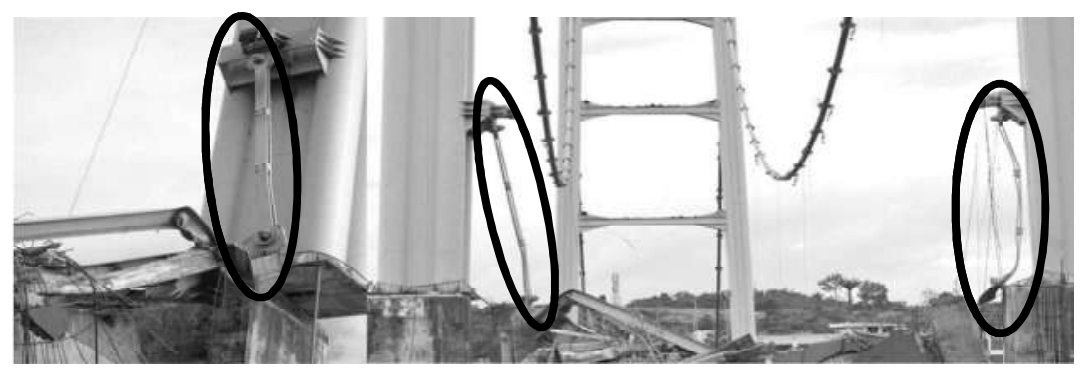

Figure 3 - Tower Strap as a Binder for Direct Bridge Frame in Steel Pilon
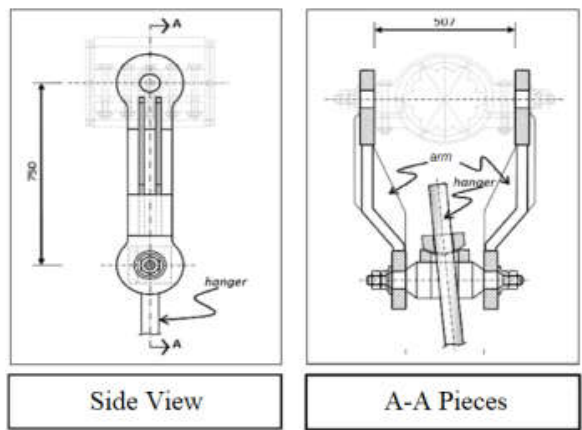

Figure 4 - Cable Bands of the Kutai Kartanegara Bridge

At the Kutai Kartanegara Bridge, the connection between the hanger and cable bands is done through clamps. Generally, this clamp consists of a pair of arms. The upper part of the arm is connected to a band through an arch that protrudes on both sides of the band. Meanwhile at the bottom, a pair of clamping arms is connected by an arch. The arch is where the hanger is based; which is right in the middle of the arch. The clamping arm material is made of FCD 60 cast iron (Ferro Casting Ductile), with strong melting $\mathrm{f}_{\mathrm{y}}=370 \mathrm{MPa}$, tensile strength $f_{u}=600 \mathrm{MPa}$, and $3 \%$ spreading. Hanger is made of steel material with strong melting $f_{y}=555 \mathrm{MPa}$ and tensile strength $f_{u}=700 \mathrm{MPa}$. Field observations show that all hanger has shown satisfactory performance; as in the case of suspension cables. There are very few hangers that are found broken in brittle mode, even though there are many crooked hangers. The hanger is made of round steel rod with screw on the outside; hanger stem diameter is $63 \mathrm{~mm}$. The screw is used as a means of connecting the hanger to the clamp or to the bridge frame bracket. In certain parts there is a coupler as a means of connecting between hangers.
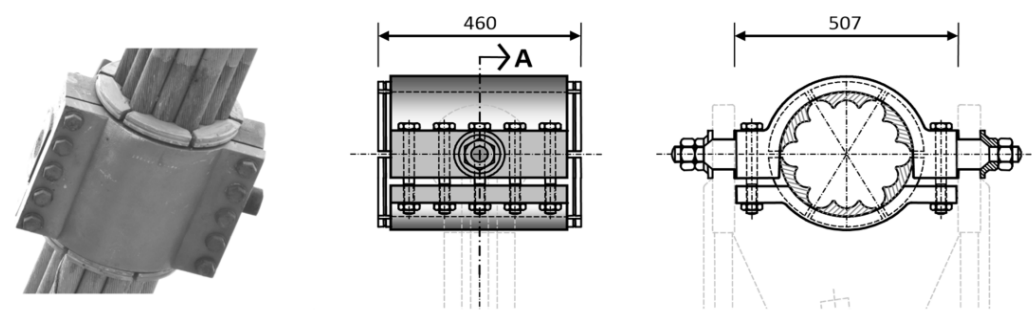

Figure 5 - Clamp and Hanger Used on the Bridge

Based on the forensic results above, the provisional estimates are as follows: 
Horizontal force components derived from suspension cables that must be carried by anchor blocks are around 1,700 - 2,200 tons per end of suspension cable or a total of 3,400 4,400 tons per anchor block.

Meanwhile, the anchor block supported by 80 pile foundations is estimated to have the ultimate lateral support of $80^{\prime} 25$ tons per pole, or a total of around 2,000 tons. The anchor block foundation on the Tenggarong side is designed as 24 meters (friction pile) deep, while the Samarinda side is set up to the final set of $25 \mathrm{~mm}$ per 10 punch (end bearing pile). It indicates that the carrying capacity of the Tenggarong side anchor block foundation is weaker than the Samarinda side.

Due to lack of carrying capacity, 3,400 - 4,400 tons vs. 2,000 tons, the failure of the anchor block foundation occurs; especially on the Tenggarong side which caused the Tenggarong side anchor block to shift towards the Samarinda side. The shift stopped after the Samarinda side expansion joint $152 \mathrm{~mm}$ closed tightly. As a result of this $15 \mathrm{~cm}$ shift, decambering has occurred in the main span of about $20 \mathrm{~cm}$. The worse situation is that the remaining force of about 1,400 - 2,200 tons starts moving gradually from the anchor block to the bridge frame. The bridge frame has turned function into a press bar and will never be able to carry this extra style. It is only a matter of time when the Kutai Kartanegara Bridge will collapse, in which the foundation failure has become one of the main causes of the collapse.

The presence of a tower strap on both pilons has 'locked' the vertical frame of the bridge. Tower strap is the cause of stiffness discontinuity, which causes the emergence of primary and secondary moments in the pilon area. The decambering movement of about 20 $\mathrm{cm}$ due to shifting of anchor blocks and an additional about $40 \mathrm{~cm}$ due to the work of a total load of about $60 \mathrm{~cm}$ in the main span was not successfully distributed smoothly throughout the landscape due to the 'lock' effect in the Pilon area and the presence of a tower strap. This results in the growth of an additional tensile force in the upper stem, an additional tensile/ compressive force on the diagonal rod, and an additional compressive force on the rootstock in the pilon area, and triggers local instability resulting from breaking of the pulling bolts, failure to pull/ press diagonal rod, or bend on the press rod. The local instability is expected to occur in structural components in the Tenggarong side pilon area downstream between the tower strap and the first interior hanger. The local instability propagates progressively and becomes a global instability which has caused catastrophic failure. The existence of a tower strap has been the main cause of the collapse of the Kutai Kartanegara Bridge.

Another cause of the collapse is the occurrence of slip on some cable bands before the incident. The slipped cable bands are observed at a location near the pilon. The vertical component of the slip has a decambering effect that is quite destructive because it is near the Pilon where the decambering effect cannot be distributed smoothly in the area due to the presence of a tower strap. The decambering effect on the Pilon area has contributed to local instability and the derivative effects as previously stated.

Simulation of the Collapse of the Mahakam II Kutai Kartanegara Bridge. The bridge collapse simulation is carried out on two different bridge frame material conditions. The first simulation uses actual bridge frame material and results in failure in both non-shifting and shifting conditions. The second simulation uses bridge frame material that has been strengthened so that there is no failure of the structure in non-shifting conditions. Further simulations are carried out to see the effect of the tower strap.

In the first and second scenarios, the bridge frame is not able to carry workloads with or without shifting. It tuns out due to the presence of a tower strap used on the bridge frame to hang it directly onto the pilon. Even if bridge frame resistance is strengthened to prevent collapse in a non-shifting condition (scenario 3), collapse still occurs when the anchor block shift occurs (scenario 4). It shows that the shift of anchor blocks has a negative impact on the overall bridge frame performance. If the tower strap is removed and there is no shift in the anchor block, there will be no failure (scenario 5). In this situation, if the anchor block shift occurs, it will only find a partial failure in the form of a failure of one top stem in the middle of the main span (scenario 6). 
Table 1 - Comparison of the Maximum Internal Force for the Critical Structure Component toward the Resistance on the Diagonal Rod

\begin{tabular}{|c|c|c|c|c|c|}
\hline \multirow{2}{*}{ Scenario } & \multicolumn{2}{|c|}{ Maximum Internal Force } & \multicolumn{2}{c|}{ Resistance } & \multirow{2}{*}{ Description } \\
\cline { 2 - 5 } & Press & Pull & Press & Pull & \multirow{2}{*}{ N } \\
\cline { 2 - 5 } & $\mathrm{MN}$ & $\mathrm{MN}$ & $\mathrm{MN}$ & $\mathrm{MN}$ & \\
\hline 1. W/O C, W/TS & $-2.08 \mathrm{E}+00$ & $2.37 \mathrm{E}+00$ & & & NG \\
2. W/C, W/TS & $-2.44 \mathrm{E}+00$ & $2.58 \mathrm{E}+00$ & & & NG \\
3. W/C, W/TS, W/S & $-2.44 \mathrm{E}+00$ & $2.57 \mathrm{E}+00$ & -1.49 & 3.03 & NG \\
\hline 4. W/O C, W/O TS & $-1.17 \mathrm{E}+00$ & $1.05 \mathrm{E}+00$ & & & OK \\
\hline 5. W/C, W/O TS & $-1.73 \mathrm{E}+00$ & $1.58 \mathrm{E}+00$ & & & NG \\
\hline
\end{tabular}

Table 2 - Comparison of the Maximum In-Force for the Critical Structure Component toward the Resistance on the Up/Down Rod

\begin{tabular}{|c|c|c|c|c|c|}
\hline \multirow{2}{*}{ Scenario } & \multicolumn{2}{|c|}{ Maximum Internal Force } & \multicolumn{2}{c|}{ Resistance } & \multirow{2}{*}{ Description } \\
\cline { 2 - 5 } & Press & Pull & Press & Pull & \\
\cline { 2 - 4 } & MN & MN & MN & MN & \\
\hline 1. W/O C, W/TS & $-1.00 \mathrm{E}+01$ & $1.03 \mathrm{E}+01$ & & & NG \\
2. W/C, W/TS & $-1.56 \mathrm{E}+01$ & $1.05 \mathrm{E}+01$ & & & NG \\
3. W/C, W/TS, W/S & $1.56 \mathrm{E}+01$ & $1.05 \mathrm{E}+01$ & -5.58 & 8.12 & NG \\
\hline 4. W/O C, W/O TS & $-4.78 \mathrm{E}+00$ & $4.62 \mathrm{E}+00$ & & & OK \\
\hline 5. W/C, W/O TS & $-8.03 \mathrm{E}+00$ & $6.55 \mathrm{E}+00$ & & & NG \\
\hline
\end{tabular}

\section{RESULTS AND DISCUSSION}

The tower strap is a massive size hanger that is used to hang bridge frames directly into the pilon. The existence of a strap tower has disrupted the internal force distribution of the components of the bridge frame structure. In addition, it is revealed that the tower strap has caused failure in four of the five scenarios.

In a scenario without a tower strap and frame, there is no bridge failure, even though the tensile force near the pilon increases due to the removal of the tower strap. The existence of a tower strap has caused great internal forces on the components of the bridge frame structure that is nearby. This is not found when the tower strap is removed. In fact, in one scenario, the bridge condition seems to be quite stable if the tower strap is removed even though the anchor block shift occurs. Thus, it can be stated that the tower strap is the main cause of bridge collapse.

The foundation of a number of 80 pile blocks has not been able to carry the horizontal component of the suspension cable pulling force totaling around 4,000 tons. The foundation failure resulted in the joint Tenggarong side anchor block shifting towards the opposite side. The shifting force was also experienced by a bridge frame that moved towards the Samarinda side and caused an expansion joint gap on the Samarinda side to close. The gap in the expansion joint's technical specification of $152 \mathrm{~mm}$ closed tightly.

Along with the closing of this gap, the tensile force of the cable which should be carried by the foundation, gradually begins to be transferred and carried by the bridge frame. The bridge has changed its function into a press rod. This style difference of approximately 1,4002,200 tons will never be able to be carried by the bridge frame and the bridge collapse is only a matter of time. Thus, it is concluded that failure of anchor block foundation is the main cause of bridge collapse.

Based on some numerical testing and analysis, it was found that the bridge frame did not have adequate detention to carry workloads. Moreover, if it is added to the effect of shifting anchor blocks. By using the actual data, the failure of the bridge frame structure component is always found in the area near the tower strap, or on one upper stem in the center of the main span; in the case without a tower strap but with shifting anchor blocks. These failures are local and can be caused by failed pull joint fractures or compressive stem bending. Thus, it can be stated that the bridge frame that does not have adequate detention has become the main cause of bridge collapse. However, in the case without a tower strap, the internal forces on the bridge frame are reduced so that they can be carried by the bridge frame adequately. 
In some cases, when a local failure occurs, redistribution occurs and causes the hanger to experience considerable additional force and then fail. The hanger failure (first interior hanger near the Tenggarong side downstream pilon) causes the bridge frame geometry to be excessively distorted and result in progressive failure of the hangers towards global instability and cause catastrophic collapse. This is not observed in tower strap simulations with anchor block shifts.

Table 3 - Simulation Scenario of the Collapse of the Mahakam II Kutai Kartanegara Bridge

\begin{tabular}{|c|c|c|c|}
\hline No & Scenario & Combination of Loads & Collapse \\
\hline 1 & Actual model + shift + tower strap & Dead + live + creep loads $(D+L+C)$ & Catastrophic \\
\hline 2 & Actual model - shift + tower strap & Dead + live loads $(D+L)$ & Catastrophic \\
\hline 3 & Strengthened model - shift & Dead + live loads $(D+L)$ & Safe \\
\hline 4 & Strengthened model + shift & Dead + live + creep loads $(D+L+C)$ & Catastrophic \\
\hline 5 & Actual model - shift - tower strap & Dead + live loads $(D+L)$ & Safe \\
\hline 6 & Actual model + shift - tower strap & Dead + live + creep loads $(D+L+C)$ & Partial \\
\hline
\end{tabular}

Note: Live load $(L)$ used are only 53\% full live load; with categories: live load (L), dead load (D), creeping load (C), and hanger shortening (S) (Standard Load AASTHO 2004).

Camber is the elevated elevation of the bridge that was deliberately given during construction. Camber is given gradually on both sides of the bridge and reaches the highest state in the middle of the span. Decambering or decreasing bridge elevation is the opposite of the word from camber. The Kutai Kartanegara Bridge decambering occurs unevenly and has been detected since 2002. In fact, there is information that decambering has been seen earlier, namely when casting concrete slabs of vehicles. The decambering process continues until 2011, with the maximum value of decambering in the middle of the span of approximately $60-70 \mathrm{~cm}$. Bridge decambering occurs due to shifting the anchor block towards the interior, the operation of the live load, and due to the slip of cable bands which mainly occurs on cable bands near the Pilon.

The unevenness of the decambering has caused changes in curvature with the greatest value in the Tenggarong side pilon area. Since changes in curvature cause secondary internal forces, this has a negative impact especially on the components of the bridge structure in the pilon area. Thus, it is concluded that decambering can increase the potential failure of bridge frame structure components in the Tenggarong side pilon area.

There are at least six instructions that indicate that the clamp has adequate resistance. However, the clamp design that tends to be complicated in terms of load transfer has caused clamping resistance to be determined by its stability. In a normal configuration, according to the initial design, the clamp will be quite strong. However, if the clamp must carry the hanger's pulling force on its side, the resistance will be greatly reduced. The sloping state occurs when the suspension cable moves transiently and the bridge frame is in a highly distorted geometry when it falls into the river. Regarding the relatively low stiffness of the suspension cable torque, two successive clamps can experience different angles when there are torsional waves propagating on the suspension cable. This can also reduce clamping resistance significantly.

If the modified clamp design becomes more reliable, it can avoid progressive collapse even if a partial failure occurs in one of the clamps/ hangers. Furthermore, it is found that if there is a failed clamp, the failure of the clamp is more likely to occur in the clamp or hanger near the pilon than the clamp or hanger in the middle of the span.

Based on the calculation results, the slip cable band on the suspension should not have occurred. However, the facts of the field indicate the existence of the slip; especially for cable band near Pilon. Slip cable band can occur due to the increased load on the hanger that occurs due to the relaxation process on the other hanger next to it. Slip cable headbands can result in decambering and secondary pull/ press forces on the upper/ lower/ diagonal trusses of the bridge frame. If the force is too large, it can break the bolts at the top/ diagonal joint, or cause bending on the lower/ diagonal rod, and trigger local instability. Local instability can progressively lead to global instability and cause catastrophic collapse. 
From the five scenarios examined for several internal forces, placement reactions, and deformations, there was no direct relationship between the lift and the bridge collapse. Furthermore, it is because the pulling force of the hanger in the middle of the span is smaller than that of the hanger near the pilon. Thus, a lift that starts at the middle span hanger is in accordance with what it should be.

At the time of the collapse, traffic is only active on one lane, i.e. the downstream lane; while the upstream side lane is released for maintenance purposes. This situation has caused longitudinal torque on the bridge frame with additional pressure on the downstream side frame, and decompression of the upstream side frame. Based on the observations, it was found that if a collapse occurred then it would start from the downstream side of the Tenggarong pilon area.

The nuts that are dropped/ released when the lift (if it really happened) can change the distribution of the hanger pull force and the hanger next to it. However, it does not break the clamps or hangers. Thus, there is no direct connection was found between the lift and the collapse of the bridge, even though there were nuts that are dropped/ released when the lift was conducted.

\section{CONCLUSION}

The main cause of the collapse of the Mahakam II Bridge in Tenggarong was the construction failure of the vertical hanging cable (clamp and saddle) connecting the main cable. However, there are a number of other possibilities that cause damage to the connecting device which includes: 1) poor maintenance, 2) fatigue in the construction material of cable hangers, 3 ) the quality of construction materials for the cable of connecting device, 4) procedural errors in maintenance, 5) the possibility of civil engineering rules deviations in planning, and 6) design errors in determining the type of material/ material of connecting device. Commonly, building damage is caused by several factors including: 1) low quality of materials, 2) planning errors, 3) implementation process errors, and 4) poor supervision.

\section{SUGGESTIONS}

The government, before carrying out a construction project, should provide land that is stable, flood-free, and far from termite colonies, provide quality building materials and good workmanship. In addition, the project executor should make regular observations to find out the damage independently, carry out routine maintenance so that the damage does not become more severe and endanger the users in the future, make sure that the wood materials used for repairs are preserved, coated with anti-oxidant materials, and provide professional and reliable workers in their respective fields.

The consultant and project supervisor should carry out their duties with full responsibility and a sense of belonging as well as implement and adhere to the civil engineering SOP properly.

For law enforcement officials, the results of forensic engineering investigations are expected to be a guideline in conducting audits of parties directly and indirectly involved in the work and events. Thus, failure resulting from negligence of executors can be avoided as early as possible and can make the deterrent effect on "naughty" executor.

The government should immediately establish a special institution that handles engineering forensics in Indonesia; considering that the establishment of this institution is urgently needed.

Academic institutions are expected to be a pioneer in initiating the establishment of the Independent Forensic Engineering Institute. 


\section{REFERENCES}

1. Wiyana, Y. E. (2016). Analisis Kegagalan Konstruksi dan Bangunan dari Perspektif Faktor Teknis. Wahana Teknik Sipil: Jurnal Pengembangan Teknik Sipil, 17(2).

2. Wahyono, H. L., Wibowo, M. A., \& Utomo, D. H. (2011). Analisis Ketidaksesuaian Kontrak Dalam Kegagalan Konstruksi Dan Kegagalan Bangunan (Doctoral dissertation, magister teknik sipil).

3. Mitchell, C. A., Carew, A. L., \& Clift, R. (2004). The role of the professional engineer and scientist in sustainable development. Sustainable development in practice: Case studies for engineers and scientists, 29-55.

4. Hobbs, B., \& Kebir, M. T. (2007). Non-destructive testing techniques for the forensic engineering investigation of reinforced concrete buildings. Forensic science international, 167(2-3), 167-172.

5. Ghobarah, A., \& Said, A. (2002). Shear strengthening of beam-column joints. Engineering structures, 24(7), 881-888.

6. Johnson, C. (2011). Creating an enabling environment for reducing disaster risk: Recent experience of regulatory frameworks for land, planning and building in low and middleincome countries. Background Paper for the Global Assessment Report on Disaster Risk Reduction, 2011.

7. Bernquist, J. (2004). Safety cage design in the VOLVO XC90. In American Iron and Steel Institute, 2004 Great Design in Steel Seminar (www. autosteel. org), Livonia, MI.

8. Sezen, H., Whittaker, A. S., Elwood, K. J., \& Mosalam, K. M. (2003). Performance of reinforced concrete buildings during the August 17, 1999 Kocaeli, Turkey earthquake, and seismic design and construction practise in Turkey. Engineering Structures, 25(1), 103-114.

9. Ellingwood, B. R., \& Dusenberry, D. O. (2005). Building design for abnormal loads and progressive collapse. Computer-Aided Civil and Infrastructure Engineering, 20(3), 194205. 